WellBeing International

WBI Studies Repository

$5-2005$

\title{
Number Comprehension by a Grey Parrot (Psittacus erithacus), Including a Zero-Like Concept
}

Irene M. Pepperberg

Brandeis University

Jesse D. Gordon

Brandeis University

Follow this and additional works at: https://www.wellbeingintlstudiesrepository.org/acwp_asie

Part of the Animal Studies Commons, Comparative Psychology Commons, and the Other Animal

Sciences Commons

\section{Recommended Citation}

Pepperberg, I. M., \& Gordon, J. D. (2005). Number comprehension by a grey parrot (Psittacus erithacus), including a zero-like concept. Journal of Comparative Psychology, 119(2), 197.

This material is brought to you for free and open access by WellBeing International. It has been accepted for inclusion by an authorized administrator of the WBI Studies Repository. For more information, please contact wbisr-info@wellbeingintl.org.

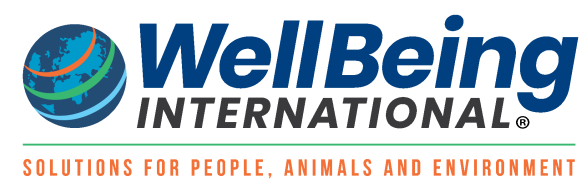




\title{
Number Comprehension by a Grey Parrot (Psittacus erithacus), Including a Zero-Like Concept
}

Irene M. Pepperberg and Jesse D. Gordon

Brandeis University

\begin{abstract}
A Grey parrot (Psittacus erithacus) that was able to quantify 6 item sets (including subsets of heterogeneous groups, e.g., blue blocks within groupings of blue and green blocks and balls) using English labels (I. M. Pepperberg, 1994a) was tested on comprehension of these labels, which is crucial for numerical competence (K. C. Fuson, 1988). He was, without training, asked "What color/object [number]?" for collections of various simultaneously presented quantities (e.g., subsets of 4, 5, and 6 blocks of 3 different colors; subsets of 2, 4, and 6 keys, corks, and sticks). Accuracy was greater than $80 \%$ and was unaffected by array quantity, mass, or contour. His results demonstrated numerical comprehension competence comparable to that of chimpanzees and very young children. He also demonstrated knowledge of absence of quantity, using "none" to designate zero.
\end{abstract}

"Number sense" requires handling abstract concepts-representations and relations (Dehaene, Spelke, Pinel, Stanescu, \& Tsivkin, 1999; Lenneberg, 1971). The subject must have a clear representation of quantity that transfers across modalities and applies to any items. Number sense is not necessarily the same as true symbolic "counting" (see Fuson, 1988; Gelman \& Gallistel, 1978), which requires subjects to (a) produce a standard sequence of number tags, (b) apply a unique number tag to each item to be counted, (c) remember what already has been counted, and (d) know that the last number tag used tells how many objects are there. Apes show simple humanlike counting and enumeration skills, though not a number sense identical to that of humans (Beran, 2001, 2004; Beran \& Rumbaugh, 2001; Biro \& Matsuzawa, 2001; Boysen \& Berntson, 1989, 1990; Kawai \& Matsuzawa, 2000; Murofushi, 1997); monkeys, pigeons, and rats seem sensitive to ordinality and numerosity (e.g., Brannon \& Terrace, 1998, 2000; Brannon, Wusthoff, Gallistel, \& Gibbon, 2001; Emmerton, Lohmann, \& Niemann, 1997; Nieder, Freedman, \& Miller, 2002; Olthof, Iden, \& Roberts, 1997; Orlov, Yakovlev, Amit, Hochstein, \& Zohary, 2002; Smith, Piel, \& Candland, 2003; Sulkowski \& Hauser, 2001; Xia, Emmerton, Siemann, \& Delius, 2001; Xia, Siemann, \& Delius, 2000; but see Dehaene, 2001); crows (Smirnova, Lazareva, \& Zorina, 2000; Thompson, 1968), coots (Lyon, 2003), orangutans (Call, 2000; Shumaker, Palkovich, Beck, Guagnano, \& Morowitz, 2001), lions (McComb, Packer, \& Pusey, 1994), and dolphins (Kilian, Yaman, von Fersen, \& Güntürkün, 2003; Mitchell, Yao, Sherman, \& O'Regan, 1985) have some number concept; and even domestic dogs appear sensitive at least to mass if not number (West \& Young, 2002). Some researchers have suggested that animals' sensitivity to number is a neutrally based, evolutionarily 
inherent skill (e.g., Dehaene, 1997), but the extent to which animals understand number when compared with young children (e.g., Mix, Huttenlocher, \& Levine, 2002b) is still unclear.

Research with Grey parrots provides another example of numerical competence. One bird, Alex, vocally produces English quantity labels for sets of up to six items including novel items, random patterns, and subsets of heterogeneous groups (e.g., number of; blue blocks within groupings of blue and green blocks and balls, Pepperberg, 1994a). This behavior is cross-modal: seeing arrays of, for example, intermixed subsets of three, four, five, and six objects; hearing "How many blue block?"; translating the phrase into a search for a specific object among many distractors; determining the numerosity; and then translating the cardinal amount viewed into the vocal label "six." His accuracy is unaffected by array quantity, mass, or contour (Pepperberg, 1987, 1994a), suggesting that simple analog-based representations of number proposed to explain most animal data (e.g., Weber's Law; see Meck \& Church, 1983) are not applicable. Supposedly, testing with heterogeneous sets precludes, at least in humans, use of nonnumerical enumeration processes (i.e., perceptual strategies such as subitizing, in which number is represented by a recognizable canonical pattern-think dominoes or dice-or neural nets proposed by Dehaene \& Changeux, 1993); that is, success on such tasks suggests an ability to count (Trick \& Pylyshyn, 1989, 1994). Parrots might, however, be more advanced perceptually than humans. Furthermore, it was not known if Alex had formed only one-directional associations (i.e., could produce but not comprehend labels, as did apes and children in some studies; Fuson, 1988; Savage-Rumbaugh et al., 1993; SavageRumbaugh, Rumbaugh, \& Boysen, 1980) or if he fully understood the interchangeability of numerical questions (comprehension as well as production); this equivalence is crucial for numerical competence (Fuson, 1988). Acquisition of such comprehension data would not conclusively determine whether Alex was counting but would provide additional evidence of his understanding of numerical symbols.

We had not intended to examine Alex's response to the absence of quantity, that is, to a zero-like concept; Alex himself initiated such trials. Zero is interesting because it lacks concrete reality and thus may emerge for children later than other numerical concepts (Bialystok \& Codd, 2000; Wellman \& Miller, 1986); specifically, number competence is based on an assumption that something exists to enumerate, whatever process is involved. Chimpanzees (Biro \& Matsuzawa, 2001; Boysen \& Berntson, 1989; Rumbaugh, Savage-Rumbaugh, \& Hegel, 1987) and possibly squirrel monkeys (Olthof et al., 1997) show some understanding of the concept. Intrigued by Alex's spontaneous, untrained use of "none" to describe a quantity that was not present, we proceeded to investigate his behavior further.

\section{General Method}

\section{Subject and Housing}

Alex, a 27-year-old male Grey parrot (Psittacus erithacus), had been the subject of numerous cognitive and communicative studies for 26 years, including those involving numerical competence (Pepperberg, 1987, 1994a). Testing locations and living conditions when neither testing nor training were in progress are described in, for example, Pepperberg, Naughton, and Banta (1998), except that now he always shared a room with two other birds (Pepperberg \& Wilkes, 2004). Food and water were available at his vocal request at all times during testing. In this study he used his previously documented ability (Pepperberg, 1999) to produce vocal labels for colors (rose [red], green, purple, blue, yellow, orange, and gray), objects (keys, toy trucks, etc.), and materials (paper, wood, cork, etc.).

\section{Apparatus}

During testing, different quantities of items were scattered randomly on the same type of tray used in previous studies on object permanence (Pepperberg \& Kozak, 1986), label comprehension (Pepperberg, 
1990, 1992), and other number capacities (Pepperberg, 1994a). In Experiment 1, we used two different colors of the same object; in Experiment 2, we used three different colors of the same object or three different objects of the same color. We, along with other experimenters, concurrently used the tray for training spatial concepts and phoneme and Arabic number recognition (Pepperberg, 2005); thus, a tray did not cue numerical trials.

\section{General Procedure: Object Presentation}

A number trial began when a human scattered the test objects randomly, by heterogeneous handfuls, onto the surface of the tray. Only if an item was completely obscured by placement of other items or if subsets obviously clumped together was the arrangement altered. Each item was less than $2.5 \mathrm{~cm}$ from the other nearest item and generally the distance was less; objects such as wooden rods or sticks often overlapped. Given the intermixed arrangement of items on the tray, the closeness of the tray to Alex's eye $(5-10 \mathrm{~cm})$, and the distance of the tray from the questioner's face $(20-25 \mathrm{~cm})$, Alex could not be cued as to the relevant subset by following eye gaze of the experimenter (e.g., Peignot \& Anderson, 1999; Vick \& Anderson, 2003). The experimenter made eye contact with Alex, who was then asked, vocally, and without any training, to respond to questions such as "What color 6?"; "What toy/matter 4?"; or "What 5?" By looking at Alex rather than at the tray while uttering the question, the experimenter further decreased the possibility of cuing via eye gaze; Alex could establish eye contact with both experimenter and tray simultaneously. Alex had previously responded vocally to such recursive questions (i.e., given a collection of objects of various materials, colors, and shapes, he answered "What object [color $x$ ]?"; "What color [object y]?"; "What shape [object z]?"; and "What object [shape q]?"; Pepperberg, 1990). The current procedure required that he translate the auditorially presented numeral (e.g., "six") into a search for a cardinal amount (e.g., six things), that is, know exactly what a set of $x$ individual items is, even if intermixed with other objects. Each question also retested his ability to identify the object or color specified by the numerical label. To respond correctly, Alex had to process all types of information without error. Some or all of this behavior likely occurred as separate steps, each step adding to the task's complexity (Premack, 1983).

\section{General Testing Procedure}

Test sessions, at most one per day, of a single numerical question (i.e., on a single array) occurred 3-5 times per week during September 2003 and November 2003-June 2004. ${ }^{1}$ Test questions were presented intermittently either during free periods (when birds were requesting various foods or interactions) or during sessions on current (and thus unrelated) topics (e.g., using Alex to train another parrot on shape labels) until all questions for the experiments were presented. As in all studies with Alex, the protocol differed from those used with other animals in that the task capitalized on Alex's ability to work in the vocal mode. Details of test procedures, including descriptions of precautions against inadvertent and expectation cuing, are summarized below; details are in previous studies by Pepperberg (1981, 1990, 1994a). A question was repeated in a session only if Alex's initial answer was incorrect (e.g., Pepperberg, $1981,1987)$. Thus the number of times an array was presented depended on Alex's accuracy. If he produced the appropriate label, he received praise and the objects to which the question referred, or he was allowed to request an alternative reward. No further presentations of the same array then occurred; that is, there was only a single, "first-trial" response. If an identification was incorrect or indistinct, the examiner removed the tray, turned his or her head, and emphatically said "No!" Only under this condition did the experimenter immediately, repeatedly present the array so as to penalize a win-stay strategy, and presentation continued until a correct identification was made or four attempts occurred; errors were recorded. One number session could thus involve up to four trials on the same question, but only if Alex erred. 


\section{Controls Against Expectation and Experimenter-Induced Cuing}

Test situations included specific precautions to avoid cuing. One control was a design such that each test session was, as noted above, presented intermittently during free periods or work on unrelated topics. We also used a wide variety of objects in testing, including those used for training the other birds; thus particular objects would not cue Alex that a number test was in progress. Alex's responses had to be chosen from his entire repertoire (>90 vocalizations, including labels for locations and foods) and from among numerous possible topics concerning various exemplars and questions during each session; each session contained only a single number array. This design not only increased task complexity but also prevented several forms of cuing (see Premack, 1976, p. 132; Pepperberg, 1999). An examiner who, for example, poses a series of similar questions may come to expect a particular answer and unconsciously accept an indistinct (and by our criteria incorrect) response of, for example, "gree" (a mix of "green" and "three") for "green." Second, in general, a human other than the one presenting the tray (one of four possible individuals in these experiments), who did not know what was on the tray, confirmed the answer; his or her interpretation of Alex's response was thus unlikely to be influenced by an expectation of a certain color or object label. Only after his or her confirmation was Alex rewarded (Pepperberg, 1981). Third, because Alex had not been trained on this task, no overlap occurred between training and testing situations, and because training on color, object, and number labels had occurred years before and involved 90 utterances, Alex could not have picked up on trainer-induced cues specific to a given label (Pepperberg, 1981); moreover, because a total of five different humans were involved in the testing, the presence of a particular individual could not cue a number session. Fourth, as noted above, the tray was not exclusively used on number trials and thus did not signal a number test. Fifth, the evaluator was unlikely to be influenced by hearing the type of question posed: In a previous study, transcriptions of contextless tapes of Alex's responses in a session agreed with original evaluations to within $98.2 \%^{2}$ (Pepperberg, 1992).

\section{Scoring}

Alex's test scores were calculated in two ways. Because the test procedure required that a question could be repeated (up to four times) until Alex produced the correct response, we scored both first-trial and alltrial responses. First-trial results were the percentage of correct responses on first trials. Overall test scores (results for all trials) were obtained by dividing the total number of correct identifications (i.e., the predetermined number of collections) by the total number of presentations required to obtain correct responses. We would score errors for trials if Alex's response was indistinct.

To learn if Alex's results were statistically significant, we used a binomial test in which chance was based on the number of labels relevant to the task, 1/2 in Experiment 1 (two possible color labels) and 1/3 in Experiment 2 (three possible color or object labels), that is, as if Alex was randomly guessing, without targeting a subset, among the labels (color, material, or object) of all presented subsets. All calculations are conservative in that they assume $100 \%$ comprehension of labels that identify the subset (i.e., that he understands the labels color, toy, and matter). A less conservative calculation would include the probability of his erring on a nonnumber label, for example, correctly comprehending the number but incorrectly labeling the relevant color or object. Given that his accuracy was $\sim 80 \%$ on color-shapematerial- object comprehension tasks (Pepperberg, 1990, 1992), the probability for such a misidentification was small but not nonexistent. ${ }^{3}$ Chance could also be based on production of all possible color or object labels, as if Alex was randomly guessing after limiting his choice to colors, materials, or objects after hearing "What color. .." or "What object/matter. . "Note, too, that Alex could have produced any other of the numerous vocalizations in his repertoire; all calculations assume that Alex will always $(p=1)$ attend and respond correctly to the "What color. .." or "What object . . ." part of the question (i.e., 
not provide a random label that had no connection to the task at hand; i.e., give a shape label; see below).

\section{Experiment 1}

Experiment 1 primarily provided baseline data for acquainting Alex with the form of the task. By using a simpler version of the full task, we could introduce the procedure without providing formal training and determine if he had some number label comprehension. Thus queries involved arrays of only two different numerical quantities and used the same type of object for each quantity in each array.

\section{Method}

The procedure was described above. Alex saw a tray on which we scattered two different colors of one type of object (e.g., red and green blocks). To simplify the task, we used the same objects for both quantities, though sizes could vary, both within and across trials (i.e., larger woolen pompons could be used for the smaller number of objects to avoid cues with respect to contour, mass, or density; see the Appendix). He was asked "What color $X$ ?"; $X$ was a number label. We used woolen pompons; plastic cups and spools; metal or plastic keys; pieces of dried pasta and paper; and wooden sticks, rods, and blocks. Alex's six number labels could be combined 30 ways, such that each was paired with every other number twice and each number was queried once for each possible collection (e.g., 4 and 6 paired twice: "What color 4?" queried one time, "What color 6?" the other). Sessions were arranged so neither a particular color (the response) nor number (the target) would be in two successive questions. Because we were particularly interested in Alex's ability to distinguish between small quantities (1 vs. 2) and small differences between larger quantities (e.g., 5 vs. 6) for comparison with children, pigeons, and monkeys (e.g., Brannon et al., 2001; Smith et al., 2003; Wakely, Rivera, \& Langer, 2000; see review in Mix, 1999), we repeated one session with each of these combinations for a total of 32 sessions.

We specifically limited the number of sessions to avoid training Alex on these queries; thus, except for the two deliberate repetitions, sessions were unique. Given that he received rewards for correct responses, however, one could still argue that Experiment 1 was a training procedure. To show whether such was the case, we report data for all trials in the Appendix. If Alex was being trained, errors would be highest in the first trials (particularly the first five) and decrease as the experiment progressed.

\section{Results}

Alex made only three errors in 32 trials ( $>90 \%$, first-trial responses, $p<.001$, binomial test, chance $=1 / 2$; in all trial responses, 32/35, >90\%). No responses were indistinct. Given the small number of both trials and errors, we initially pooled results for all number pairs for analysis. Because we kept sessions per label low to avoid training, statistics per number label are not meaningful.

We separately examined errors in blocks of 5 and 10 trials and for pairs that differed by one or two integers. He made no errors on the first 5 trials, one error in the first 10 trials, and one error in each of the subsequent 10 trials. He erred once on 2 versus 3, once on 4 versus 6 , and once on 5 versus 6 ; he made no errors on 1 versus 2. For all trials in which the difference was one (12 trials in all), his accuracy was $83.3 \%(10 / 12, p=.016$, binomial test, chance $=1 / 2)$; on one of these trials ( 5 vs. 6$)$, however, his response was random, that is, was a color not presented on the tray. For all trials in which the difference was two ( 8 trials in all), accuracy was $87.5 \%(7 / 8, p=.035$, binomial test, chance $=1 / 2)$. 


\section{Discussion}

Alex could perform the task. Errors were not consistent with an interpretation of either training or nonsymbolic response. The data, albeit limited, imply some level of numerical label comprehension.

Alex was not likely trained on comprehension during the experiment, nor did he require training to do the task. He made very few errors, none within the first 5 trials and only one within the first 10 trials. He was unlikely to have learned anything from his first error on 5 versus 6 , because he did not choose the wrong response; he gave an irrelevant one, suggesting a lack of attention. If he were guessing at the answer, he would likely have chosen one of the color labels that was present.

Nor are his errors fully consistent with a perceptual mechanism-that he viewed the collections as humans view dots on dice or dominos and recognized the quantity without counting (Gallistel \& Gelman, 1992; Mandler \& Shebo, 1982; Seibt, 1982; von Glasersfeld, 1981, 1982). A perceptual mechanism would predict that he would have erred far more for collections in which the two sets differed by one or two than for collections in which the difference was greater, and even more likely, that he would have erred more for overall larger rather than smaller arrays. Although all errors were for differences of one or two, only three errors were made, the error involving the largest collection was a random response, and overall he was better than chance on these trials (20 in all). His error for 2 versus 3 , for example, was not made the first time these items were paired. According to Mix et al. (2002b), even young children cannot exactly mentally represent sets of larger sizes (e.g., above about four), which would enable them to use a perceptual mechanism. Of course, parrots might have better perceptual mechanisms than children. We further discuss Alex's possible use of a perceptual mechanism below.

A previous potential error source in some experiments involved differences in human versus parrot color perception. Parrots see colors in the ultraviolet spectrum that are unavailable to humans (e.g., Bowmaker, Heath, Das, \& Hunt, 1994; Bowmaker, Heath, Wilkie, Das, \& Hunt, 1996; Pepperberg, 1994a), and occasionally some objects, because of the specific type of colorant used in their manufacture, might therefore be misidentified. Such an issue was not likely in this experiment: Potential confusions, of orange with either yellow or red or of purple with either red or blue, were not in evidence.

Arguably, use of identical items for both quantities to simplify the task might have allowed Alex to respond on the basis of mass or contour, not number (Brannon \& Terrace, 2000; Feigenson, Carey, \& Spelke, 2002; Mix, Huttenlocher, \& Levine, 2002a; Smith et al., 2003). Such an interpretation is, however, unlikely given that trials involved different items for various arrays. For example, we used cups in some trials, wooden sticks in others, and, on occasion, different sized items both across and within trials; the smaller number could have the larger sized item(s). Furthermore, the task did not require relative judgments. Thus, unlike other nonhumans and children, Alex was not asked to choose a bigger array or to order sets of items with respect to number; he had to understand labels for exact quantities. Only if he already knew ordinality-for example, that the label 2 represented a quantity less than the label 5-could he respond on relative mass rather than exact quantity, but he had no training on ordinality, nor had he learned number labels in order of magnitude (i.e., he learned 3 and 4 first; Pepperberg, 1987). We were also careful that successive questions involving the same number pairs used different objects or, in one case, different sized objects.

Nevertheless, the point of this experiment, as noted above, was less to test Alex's numerical competence than to provide a simple task to accustom him to the type of question being posed. Because parrot perceptual mechanisms could be more robust than those of humans, a stronger task was necessary to demonstrate conclusive comprehension of number labels: hence, Experiment 2. 


\section{Experiment 2}

Experiment 2 was designed to test if Alex indeed comprehended number labels. Now he saw and was queried about either the color or the material- object for one of three different sets of intermixed quantities so integration of items would be more complex (e.g., one green key would not contrast so clearly against a field of six blue ones, because two red keys could be intermixed). Too, although we do not know if Alex uses color as a preattentive feature to separate sets (i.e., a pop out; Treisman \& Gelade, 1980; Treisman \& Souther, 1985), those trials using different objects of one color (objects being defined by a conjunction of features) would require serial, nonpreattentive, search. That is, the additional complexity would increase both discriminative and cognitive loads (e.g., Lavie \& de Fockert, 2003), making use of perceptual mechanisms unlikely (Pepperberg, 1994a; Trick \& Pylyshyn, 1989). Moreover, because different types of objects were used, contour across subsets would differ significantly, and mass of the larger quantity now could more easily be made smaller than that of the smaller quantity, further removing possibilities of Alex using mass or contour as a nonnumerical cue.

\section{Method}

The procedure was described above. Alex saw a tray on which we scattered three different colors of one type of object (e.g., red, blue, and green blocks) or three different types of objects of one color. He was asked "What color/matter/object $X$ ?"; $X$ was a numerical quantity. We used plastic cups, rings, and spools; metal or plastic keys; metal toy trucks; pieces of dried pasta, chalk, and paper; woolen pompons; jelly beans; candy hearts; corks; paper tubes; and wooden sticks, rods, rings, clothes pins, and blocks. When possible, objects varied in size within trials. Alex's six number labels could now be combined 60 ways, such that sets of numbers occurred three times and each number was the subject of query once for each possible collection (e.g., 1, 4, and 6 grouped three times; "What color 1/4/6?"' each asked once). Queries were arranged so neither a particular color or item (the response) nor number (the target) was involved in two successive sessions. Again, we limited the number of sessions to avoid the possibility of training Alex on a particular set of questions; thus each session was unique; we again interspersed trials within other types of interactions in the laboratory. During testing, we had to add six sessions to accommodate an additional query instituted by Alex (see below).

\section{Results}

Noncompliance. After responding without error in eight trials (at least one for each targeted number), Alex completely balked during testing for approximately 2 weeks. He would, for example, stare at the ceiling, reply with a color or object label not on the tray, fixate on that label, and repeat it endlessly; this behavior was interspersed with requests to return to his cage or with requests for water or various foods. (NB: We always acquiesced to food and water requests.) He might produce labels for each of the four colors not on the tray, that is, carefully avoid any response that could be construed as task related (NB: such behavior is statistically unlikely to occur by chance; Pepperberg \& Lynn, 2000). Occasionally he called out numbers that might or might not be relevant. We tried using what we thought might be more enticing items (e.g., jelly beans) to no avail. These trials clearly differed from other number trials in that he would neither maintain his gaze at the tray nor make eye contact with the questioner. At the end of this period, he returned to testing, although he might still repeat such behavior, sometimes once or twice a week. When Alex has demonstrated such behavior in other situations (usually during training but sometimes during testing; Pepperberg, 1992; see discussion in Pepperberg \& Lynn, 2000), we discounted the trials, and we did so again here. ${ }^{4} \mathrm{Had}$ his responses been errors tied to the trials, they would have been counted. Each of the 16 discarded trials was, however, repeated at a later date with different objects and colors, so that all collections were tested eventually. We suggest reasons for Alex's behavior in the Discussion below. 
Table 1. Results and Errors for Experiment 2

\begin{tabular}{|c|c|c|c|c|c|}
\hline No. & Score & $\%$ & $p$ & Trial type $^{a}$ & Error descriptions \\
\hline 1 & $8 / 10$ & 80 & $<.005$ & $\begin{array}{l}1 \mathrm{O}, 2 \mathrm{P} \text {, and } 5 \mathrm{G} \text { paper rings } \\
1 \mathrm{P}, 4 \mathrm{Y} \text {, and } 6 \mathrm{O} \text { jelly beans }\end{array}$ & $\begin{array}{l}\text { Stated } Y \text { not } O \text {, no } Y \text { present } \\
\text { Stated } Y \text { not } P, Y \text { was } 4\end{array}$ \\
\hline 2 & $9 / 10$ & 90 & $<.001$ & $2 \mathrm{~B}, 5 \mathrm{O}$, and $6 \mathrm{~Gy}$ jelly beans & Stated O not B \\
\hline 3 & $10 / 10$ & 100 & $<.001$ & & \\
\hline 4 & $8 / 10$ & 80 & $<.005$ & $\begin{array}{l}3 \mathrm{P}, 4 \mathrm{O} \text {, and } 6 \mathrm{R} \text { rods } \\
1 \mathrm{Y}, 3 \mathrm{R} \text {, and } 4 \mathrm{P} \text { rods }\end{array}$ & $\begin{array}{l}\text { Stated } R \text { not } O, R \text { was } 6 \\
\text { Stated } B \text { not } P \text {, no } B \text { present }\end{array}$ \\
\hline 5 & $8 / 10$ & 80 & $<.005$ & $\begin{array}{l}2 \text { key, } 4 \text { spool, and } 5 \text { wood } \\
2 \text { truck, } 5 \text { chalk, and } 6 \text { pegwood }\end{array}$ & $\begin{array}{l}\text { Stated wool not wood } \\
\text { Stated truck not chalk }\end{array}$ \\
\hline 6 & $10 / 10$ & 100 & $<.001$ & & \\
\hline None & $5 / 6$ & 83.3 & $<.005$ & $2 \mathrm{P}, 4 \mathrm{G}$, and $5 \mathrm{Y}$ cups; what color 1 ? & Stated $O$, no $O$ present \\
\hline
\end{tabular}

Note. Chance was $1 / 3$, except for none, for which chance was $1 / 4$. $\mathrm{O}=$ orange; $\mathrm{P}=$ purple; $\mathrm{G}=$ green; $\mathrm{Y}=$ yellow; $\mathrm{B}$ = blue; Gy = grayish black; $\mathrm{R}$ = red (Alex calls this "rose"; Pepperberg, 1981).

a Jelly beans were both standard and miniature sized. Wooden rods were $5-10 \mathrm{~cm}$ long and $0.32 \mathrm{~cm}$ in diameter.

"Wood" refers to popsicle sticks 5-8 cm long. "Pegwood" is Alex's label for a clothespin. Cups were of different sizes: two large, four medium, and five small.

General results. After removing trials of complete nonattention, we found that Alex made eight errors in 66 trials $(87.9 \%$, first-trial responses, $p<.001$, binomial test, chance $=1 / 3)$. For all trials, he scored $66 / 74$ (89\%). Scores for each targeted number are in Table 1. He made no errors on the first 10 trials, two errors in the second 10 trials, one in each 10 of the subsequent 20 trials, two in the next 10 trials, and two in the last 6 trials. No responses were indistinct. His error pattern suggested lack of focus or inattention as testing proceeded, not that he had learned from mistakes. On the 18 of 66 trials with different objects of the same color, he made two errors $(88.9 \%$, first-trial responses, $p<.001$, binomial test, chance $=1 / 3$; for all trials, 18/20, 90\%), compared with six errors in 48 trials $(87.5 \%, p<.001)$ for differently colored objects. Thus he did not score differently when color (i.e., an attribute for a possible preattentive mechanism; Treisman \& Gelade, 1980) was not a discriminant.

Alex erred on trials in which a targeted number differed from another subset quantity by small amounts, but errors may not have been numerical. He made one error on 1 versus 2 (a yellow- orange error, but nothing was yellow), no errors on 2 versus 3, two errors on 3 versus 4 (in one case, a red- orange error, and his error was for the color of the six items, not the 3 vs. 4 discrimination itself; in the other case, a blue-purple confound, where nothing was blue), one error on 4 versus 5 (a wood-wool error, where no wool was present), one error on 4 versus 6 (i.e., the 3 vs. 4 trial), and one error on 5 versus 6 (a truckchalk error, and the error was to the two trucks, not the six clothespins). Thus no uniquely numerical errors were made within a pair differing by one item; only one possible numerical error was made to a pair differing by two items. Excluding trials involving none (see below), for trials in which the number of targeted items differed from only one set of distractors by a single item (e.g., target was 3 , and distractors were 1 and 4), his score was 25/30 (83\%, $p<.01$, binomial test, chance $=1 / 3)$, but no error labeled that distractor. When the targeted item differed from both sets of distractors by a single item, his score was $4 / 4$. When we omit trials involving the two previous criteria, for tests in which the difference from the target was two items for at least one set of distractors, he scored 13/13. 
Absence of quantity. On the 10th trial within the first dozen, Alex was asked "What color 3?" to a set of two, three, and six objects. He replied "five"; the questioner asked him twice more and each time he replied "five." The questioner, not attending to the tray, finally said "OK, Alex, tell me, what color 5?" Alex immediately responded "none." Alex had been taught to respond "none" if no category (color, shape, or material) was same or different when he was queried about the similarity or difference of two objects (Pepperberg, 1988a) and had spontaneously transferred this response to the query "What color bigger?" concerning two objects of identical size in a study of relative size (Pepperberg \& Brezinsky, 1991), but he had never been taught the concept of absence of quantity or to respond to absence of an exemplar. ${ }^{5}$ We thus repeated the question randomly throughout other trials with respect to each possible number to ensure that this situation was not an odd happenstance. On these none trials, Alex's accuracy was $5 / 6$ (83.3\%; $p<.01$, binomial test, chance $=1 / 4$ [the three relevant color labels plus none]). His one error, interestingly, was to label a color not on the tray.

\section{Discussion}

Alex succeeded on the task even with added complexity. Our use of different objects and objects of differing sizes likely precluded responses based on mass, density, or contour (Mix et al., 2002a), and our use of heterogeneous sets also likely precluded use of simple perceptual strategies (e.g., Trick \& Pylyshyn, 1989). Alex did make some errors, and we discuss their import.

Errors based on differences in human and parrot color perception (Bowmaker et al., 1994, 1996; Pepperberg, 1994a) did seem to arise. Potential confusions-orange with yellow and red, and purple with red and blue-possibly caused three of eight errors. For two of three errors, Alex's response was a color not present (e.g., "yellow" when the answer was "orange"; other colors present were purple and green), which suggests the issue was color, not numerical competence. Notably, these color errors occurred for very slightly novel items-commercially dyed paper rings and sticks used to increase, at least somewhat, reward novelty. Normally, potentially confusing color exemplars are hand dyed with a consistent set of nontoxic paints or food colors or are familiar items (e.g., plastic cups) on which color concordance has been reached.

Another source of error may have involved labels that differ little phonologically. In previous studies, Alex had rarely, but occasionally, confounded labels with similar endings, such as "block" and "rock," or those that sounded initially similar, as in "wool" and "wood" (Pepperberg, 1990). Here, one error was "truck" for "chalk" (which Alex produces like "chock") on the first trial; another error indeed involved "wool" for "wood." We should not have used these combinations in the same trial, but having done so, we found that Alex may have been confused by this added dimension of similarity.

As noted above, trials in which Alex refused to attend to experimental material and/or fixated on irrelevant issues were discarded. His behavior was unlikely a consequence of trials being too difficult; he had already succeeded on trials of equal or greater difficulty (e.g., distinguishing among similar quantities, such as four, five, and six items or one, two, and three items), and refusals to work were as likely to occur on simple trials (e.g., distinguishing among one, three, and six items) as on difficult ones. Alex's inattentiveness and consequent inaccuracy often has two causes. First, he often responds negatively to lack of novelty of the rewards. Although we used novel combinations of items in each trial, each item, by necessity, was familiar because Alex had to be able to label all attributes, so that he could not be cued as to what type of question would be asked (e.g., "What color?" vs. "What matter?"). Too, he had already completed 32 related trials in Experiment 1 . As in previous studies, when familiar objects are repeatedly used as rewards, Alex ceases to work, begins to preen, or interrupts with requests for other items ("Want $X ")$, random responses, or changes of location ("Wanna go $Y^{\prime \prime}$; e.g., Pepperberg, 1988b). In contrast, Alex's attention span often increases and accuracy improves on transfer trials, which by definition 
incorporate novel (i.e., conceivably more interesting) items (Pepperberg, 1990). Too, Alex often seems to find reward in experimenters' reactions when he persists in providing incorrect answers (most often, carefully avoiding a correct response; Pepperberg \& Lynn, 2000). We have learned that on occasion, emphasizing that the correct response will allow him to request a desired reward or action (e.g., showing how we respond when another parrot performs a simple identification trial) will eventually cause him to return to attending to the task at hand.

Alex's behavior brings up the issue of latency to respond. In many studies, researchers use such latencies to distinguish between subitizing and counting, arguing that the mechanisms for these two processes require different time frames, with subitizing requiring less time than counting (e.g., Mandler \& Shebo, 1982). Latency to response is not, however, a viable criterion for Alex. As reported previously (e.g., Pepperberg, 1987, 1988a), his readiness to respond to a given set of exemplars correlates with his level of interest in obtaining these items rather than any other factor. The familiarity of exemplars in the numerical tasks generally precluded Alex's interest in obtaining the items; he generally requested a nut or a cork after completion of a trial and ignored the targeted exemplars. Latency of response thus could be neither meaningfully measured nor compared with those of other subjects.

Of particular interest was Alex's spontaneous initial use of "none" and subsequent capacity to repeat this behavior accurately. As noted above, he had been taught to use "none" to indicate absence of information in one situation and, without training, transferred its use to another when specifically queried (Pepperberg, 1990; Pepperberg \& Brezinsky, 1991). In the present study, however, he not only provided the correct response but also set up the question himself. We had not trained the conventional term, zero, to indicate the absence of quantity; Alex's use of "none" for this purpose was unexpected. We discuss implications of this behavior more fully in the General Discussion.

\section{General Discussion}

Our data show that Alex's number label comprehension matches his level of production; that is, he understands what his number labels represent. He thus differs from children up to about 3.5 years of age, who, for example, may point to each item in a set, state "one, two, three," but not understand that three items actually are present (Fuson, 1988). How his capacities compare with those of somewhat older children is unclear; children above 3.5 years of age appear to understand number labels fully and have generally begun to count in the traditional sense (Fuson, 1988; Wynn, 1990). We do not yet know if his understanding of number matches that of chimpanzees, who add and subtract (Boysen \& Berntson, 1989). He seems to have little difficulty with numbers differing by small amounts. Five of his eight errors do appear in such trials, but some may be due to color perception or phonological confusion. Arguably, his inattentive responses on omitted trials (in contrast to errors likely due to color perception or phonemic confusion or his stating an absent color instead of "none" for an absent quantity) might represent a statement of uncertainty when given a difficult choice, but we see no reason why he would not simply have guessed, using one of the three color or object labels present. His use of "none" in a zero-like manner was noteworthy, in that it arose spontaneously and showed he understands that none represents absence of objects as well as information. Given that Alex was not trained on the comprehension task, his results are compelling. Whether his training in human speech use affected his results is also important. We discuss these issues and suggest future experiments.

\section{Comparisons With Children and Other Animals}

Comparing Alex's data with those of other species is somewhat difficult, because only children and chimpanzees have been given tasks even somewhat comparable to Alex's-that is, tasks that require exact representation of number labels and that involve language or language-like capacities. Various 
nonhuman primates (e.g., Beran \& Rumbaugh, 2001; Brannon \& Terrace, 1998, 2000; Olthof et al., 1997; Smith et al., 2003) can order numerical patterns or symbols, sequentially construct a set to correspond to a given number symbol, and even decide which combinations of items represent more versus less, but only apes have had to view a numerical symbol and choose a set containing the exact number of items to which it corresponds (Ai: Biro \& Matsuzawa, 2001; Sheba: Boysen \& Berntson, 1989); furthermore, only Ai had to choose among arrays having more than four items. Specifically, most other studies involve "constructive" number sense, which involves acting sequentially a certain number of times when shown a numerical symbol (possibly involving sequential subitizing; Burns, 1988), or responses requiring some variation of more-versus-less reasoning. Children in Wynn's (1990) study, for example, were shown large numbers of objects, then asked to "Give me X"; success was age dependent. Responses of pigeons trained to associate numerosities with symbols (Xia et al., 2000, 2001) showed a distribution around the correct answer, demonstrating a nonexact sense of quantity; birds did not transfer well to novel sets of items to be enumerated, and because enumeration involved physical pecking, they might have used sequential subitizing. No other subject has been given Alex's heterogeneous, intermixed arrays and queried on comprehension, and no nonhuman subjects have been vocally tested on number symbols.

Studies of other species show that subjects generally have more difficulty separating quantities that differ by small amounts, particularly as quantities to be compared increase in value (see Mix et al., 2002b; Olthof et al., 1997). Arguably, Alex may have similar issues. His errors on such small differences, however, may be attributable to phonemic errors and yellow- orange and blue-purple confounds, which relate more to his vocal and visual systems rather than to his numerical competence.

\section{Use of None}

Alex does not know the label zero; use of none to denote absence of a particular quantity was thus impressive for at least four reasons. First, labeling a null set, whether by zero or none, has an intriguing human history: ". . . it was not spontaneously obvious in earlier cultures that zero is a quantity that could be represented" (Bialystok \& Codd, 2000, p. 119). That zero was represented in some way by a parrot, with a walnut-sized brain whose ancestral evolutionary history with humans likely dates from the dinosaurs, is striking. Second, the notion of none, even if already associated with absence of similarity and difference (and lack of size difference; Pepperberg \& Brezinsky, 1991), is abstract and relies on violation of an expectation of presence (Pepperberg, 1988a); that Alex transferred the notion from other domains to quantity, without training or prompting by humans, was unexpected. Third, if parrots represent quantity in a manner like that of children, then Alex's comprehension of zero-none should have lagged behind comprehension of other small numbers (Wellman \& Miller, 1986). Children do seem to have a concept of none-nothing before they understand this quantity has a special label, zero (Wellman \& Miller, 1986), and Alex was not taught "zero"; nevertheless, he deliberately used "none" in a number comprehension task. ${ }^{6}$ Finally, and likely most important, we did not initiate the topic. He insisted on stating "five" when asked about "three"; when asked about the nonexistent "five," he responded appropriately. We cannot determine what cognitive processes led to this behavior. We suggest only that his action, occurring soon after a period of noncompliance, resulted from lack of interest in the given task and was a possible attempt to make the procedure more challenging. It is of interest to note that Alex, when noncompliant, occasionally stated, then repeated, all colors not present on the trial; such behavior may have been a precursor to use of "none." We cannot claim that Alex understands none or zero in an ordinal sense; young children and apes have some difficulty with ordinal use of zero (Biro \& Matsuzawa, 2001; Wellman \& Miller, 1986), and understanding the relationship between cardinal and ordinal meaning is a hallmark of abstract numerical sense (Gelman \& Gallistel, 1978). 


\section{General Discussion of Number Competence}

According to current numerical competence models, at least five interpretations exist for our data: Alex may be (a) subitizing; (b) using some form of accumulator model (Meck \& Church, 1983), in which a switch gates individual pulses into a mental "container" for each item and the total number is represented by the fullness of the container; (c) using an object-file representation (Kahneman, Treisman, \& Gibbs, 1992), in which each item is denoted by a token and the tokens form some symbolic analog for each quantity in question - this array can then be used as a reference for other sets to be quantified; (d) counting according to conditions described by Trick and Pylyshyn $(1989,1994)$ and Gallistel and Gelman (1992); or (e) using some combination or intermediary of these processes.

Subitizing. Alex could be subitizing if avian visual numerical perceptual capacities are superior to those of humans. For example, Alex might perceptually segregate the set to be enumerated (e.g., Treisman \& Gelade, 1980), which he then subitizes (Dehaene \& Changeux, 1993). For subitizing, he would need to use separate search patterns for each number he hears and to individuate each color or object set on the tray to search for and find that pattern. For numbers such as 6, several patterns are possible. Even with subitizing, such a system requires considerable cognitive processing. As noted previously (Pepperberg, 1994a), avian number perception may surpass that of humans in the auditory, sequential mode (May, 1995; Thompson, 1968, 1969; Wolfgramm \& Todt, 1982); such ability might transfer not only between auditory and visual modes but also between sequential and simultaneous processes (e.g., Seibt, 1982). Gallistel and Gelman (1991), in their interpretation of subitizing, suggested that the property of mental magnitude that represents numerosity (the distribution of magnitudes to which a digit maps) scales linearly with mean magnitude of numerosity. Thus, if Alex were subitizing, accuracy for smaller numbers would be greater than for larger numbers, and we would see a strong correlation between the severity of errors and increases in quantities to be identified (see Olthof et al., 1997). But his accuracy does not vary across quantities (he made the same number of errors on 5 as on 1), and no apparent correlation exists between numerosity and severity of errors (he made no errors on 6); his few errors involving larger quantities can equally well be a consequence of phonemic or perceptual (color) issues. Comparable performance cannot, however, ensure comparable mechanisms across species, because procedures that control for alternative explanations of behavior in one species may not provide controls in others. To ensure that Alex was beyond the subitizing range, we would have to test him on visual simultaneous quantities larger than those perceived sequentially, either auditorially or visually, in nature. Data on how Grey parrots process natural quantitative information are, however, nonexistent. An additional related possibility, proposed by von Glasersfeld $(1981,1982)$, involves mentally parsing object groupings of four or more into smaller sets, which are then subitized and added; such a system requires an understanding of addition, and we do not yet know Alex's competency in that regard.

The accumulator. This process, proposed initially to enumerate sets of discrete events (numbers of sequential tones or a continuous amount of time; Meck \& Church, 1983), claims that the same mechanism is used for counting and timing; for a static visual array, scanning of each item in a set would constitute an event, carried out at a constant rate. We could posit that on hearing a number label, Alex sets an accumulator that then must be filled by searching in turn for individual items forming each set presented to him, discarding sets that do not match. The accumulator is, however, inherently inexact because of variability in the rate of tallying events for heterogeneous arrays (see Mix et al., 2002b). Even if Alex used color as a preattentive feature to distinguish a subset (Treisman \& Gelade, 1980), he still would have to tally events. This system is unlikely to provide exact numerosities required by Alex's task: An accumulator model would likely result in errors normally distributed around the correct response and, as in subitizing, show increasing errors with increasing set size. 
Object file. In this system, each label corresponds to some mental array to which a subject compares the observed set of physical items to be enumerated (Kahneman et al., 1992; Thomas, 1992; Trick \& Pylyshyn, 1994). The subject need not have an abstract sense of, for example, fourness, but rather makes one-toone correspondences with a grouping retrieved from memory; the process is thus thought to be limited to at most four items. Unlike subitizing, it does not rely on pattern recognition, and according to some researchers (e.g., Simon, 1997), no individual symbols label the numerosity of different groupings. In general, this system is posited for situations in which individuals must make same-different judgments with respect to quantity (see Mix et al., 2002b). Even if Alex's memory allows him to form groupings of up to six, his symbolic understanding (production) of number labels and the present task requirements would not be fully consistent with such a mechanism.

Counting. If Alex does not have an unusually robust perceptual mode or extremely good short-term memory, his data are consistent with counting rather than other processes. Nevertheless, we still have no data on ordinality, nor can we claim that he understands one-to-one correspondences. We also do not yet have solid evidence that he can transfer to simultaneous visual or auditory patterns.

Other posited processes. Huttenlocher, Jordan, and Levine (1994) proposed a system for children who are just beginning to use and comprehend number symbols: The children use mental tokens that explicitly represent entities in a set while omitting irrelevant features (e.g., attributes, spatial arrangement of individual items). Unlike the object file, representations now provide conceptual referents for count words (Mix et al., 2002b), that is, allow for both one-to-one concordance and initial symbolic representation. ${ }^{7}$ If Alex's number labels are not fully equivalent to those of normal human adults, they may be equivalent to tokens of children who are just beginning to understand correlations between count words and numerosities $\geq 4$. If Alex were using this model for the present task, he would need to individuate sets of colors or objects among the intermixed, heterogeneous arrays; successively look for a one-to-one match to the model called up by the vocal label; and then produce the required color or object label. Such a process would not be less accurate for larger numbers and could be consistent with his data; the process would, however, be distinct from counting. The process also does not require that the relationshipsordinality—among the different numerosities be understood (Simon, 1997).

Because Alex had no time constraints, he may, as previously noted (Pepperberg, 1994a), have combined several processes. He could have used any of the above perceptual processes to overcome the distractor effect for quantities $\leq 3$ and then switched to a more accurate strategy for $\geq 4$. Such a combination would be particularly intriguing: Alex would, then, have shown a numerical competence not unlike that of humans, whose strategies depend on the amount to be quantified (Fuson, 1988).

\section{Effects of Language Training}

Does general label training affect the ability to quantify sets and comprehend number symbols? Some researchers (Carey \& Spelke, 1994; Hurford, 1987) have suggested a close correlation between labeling and number skills, proposing that numerical cognition is ". . . a layered modular architecture, the preverbal representation of approximate numerical magnitudes supporting the progressive emergence of languagedependent abilities such as verbal counting ..." (Dehaene, 1992, p. 35) and that "Humans may have the same initial number capacities as other animals but may develop new number representations through the use of a specific language. The language faculty, operating in conjunction with the cognitive systems that humans share with other animals, underlies distinctively human knowledge of number" (Spelke \& Tsivkin, 2001, p. 46). Alternatively, label acquisition may direct children (and, by implication, label-trained nonhumans) to attend more closely to characteristics involved in set formation (e.g., Waxman \& Markow, 1995; see review in Mix et al., 2002b), and thus such acquisition provides preparation for dealing with number sets. Of interest is that functional magnetic resonance imaging studies (Dehaene, Piazza, Pinel, 
\& Cohen, 2003) suggest that particular human brain areas are involved in semantic representations of quantity; so far, no one has searched for analogous avian structures. Might Alex's extensive training on labeling tasks nevertheless have enabled him to exhibit behavior (e.g., Premack, 1983) unlikely in a "preverbal" bird?

How Alex's use of vocal English labels affects his numerical competence is not simple to determine. Most language-related issues suggest both parallels and differences between Alex and children, other issues distinguish him from nonhuman primates and provide closer comparisons with children, and some distinguish him from pigeons. We discuss these issues below.

Of importance is that although Alex uses and comprehends, in appropriate situations, abstract utterances at a representational level, his behavior is not isomorphic with human language (Pepperberg, 1999). Most likely, his ability to separate out, visually collect, and enumerate items in a targeted subset is a consequence of his years of task-oriented training and is not special to labeling. If, as Rice (1980) argued, linguistic input cannot teach a nonlinguistic concept for which a subject is unready, then Alex likely had some underlying number concept unrelated to labeling. But what is the extent of this concept? Clearly, his ability to label quantities allows us to test his comprehension in a manner similar to that used with humans and may also help him form more precise representations of quantity in a subset. Alex can use "six," for example, to label an appropriate number of objects and can also hear the label and choose the set from a heterogeneous array that corresponds to that quantity. Unlike pigeons, Alex's responses are closely tied to the exact numbers and his errors do not form a distribution around the correct response but are numerically random. ${ }^{8}$ And, unlike nonhuman primates (e.g., Hauser \& Spelke, 2004), Alex's understanding of his labels seems not to be completely domain specific, given his transfer of the use of "none" from absence of information to absence of objects. Do these data support the view that language training assists cognitive development (Premack, 1983)?

On the one hand, our data can be interpreted to suggest somewhat closer parallels between Alex and humans. Some researchers (Carey, 2004; Hermer-Vazquez, 1997; Spelke \& Tsivkin, 2001) have argued that language allows humans to integrate information across the two systems they posit for dealing with small $(\leq 4)$ and large $(>4)$ number sets; animals also have these modular representations but, lacking language, cannot integrate their knowledge. Supposedly, one language-independent representation handles exact distinctions up to and including 4 by tracking individual members of a set, after which another language-independent system dealing with approximate numerosity must take over; the latter system fails to represent each member of such a set as a persisting individual (Spelke \& Tsivkin, 2001) and thus cannot accurately be used for larger quantities. (NB: The systems seem to relate, respectively, to subitizing and estimating; Davis \& Pérusse, 1988.) In this view, emerging language abilities (reference and ordering of labels) allow children to integrate knowledge of quantity in the small sets with their initially rotely memorized number sequence to form one-to-one correspondences-that is, generate symbolic representations of number-that can be extended to larger amounts and thus achieve accuracy for sets above four elements. If so, Alex's training on symbolic number labels, even if lacking in ordinality, may have enabled him to succeed on the current task, despite a brain organized at least somewhat differently from those of nonhuman primates and other mammals (see Reiner et al., 2004).

On the other hand, a clear distinction is that Alex's number labels are taught as referents for appropriate collections of items; the labels are not rotely, nonreferentially memorized and then attached to quantities as posited for children. An attempt to train him on a number sequence in this manner failed (Pepperberg, 1994b). Not only did he take an unusually long time to learn the nonreferential sequence, but he could not then be trained to map it to quantity. Whether this failure was an artifact of a general change in procedure or, as has been argued, was instead a consequence of a need for enhanced input for vocal learning that is deemed "exceptional" (i.e., any learning that is not likely to proceed in the normal course of 
development; see review in Pepperberg, 1999), we suggest that Alex's abilities might provide an important parallel not with normal children but with those who have trouble learning language and counting skills (note Geary, Hamson \& Hoard, 2000; Pepperberg \& Sherman, 2000).

A slightly different but related view (Wiese, 2003) is that language allows humans to advance from iconic representations of cardinality to full symbolic understanding of the generalized concept of number. Early iconic representation involves one-to-one mapping of the sequence of number words or symbols to each item to be counted (i.e., forming verbal tallies) and requires understanding ordinality but, unlike Carey's and Spelke's proposals (Carey, 2004; Carey \& Spelke, 1994; Spelke \& Tsivkin, 2001), does not initially require a subject to understand the specific meaning of any number words, that is, cardinality. Only after a child has acquired some level of nonnumeric symbolic linguistic competence will full comprehension of, for example, the number word six emerge. Studies with children who are asked to "Bring me six" suggests that both comprehension and production (i.e., "How many?") of exact number labels $\geq 4$ emerge at about 3.5 years of age; by that time, children already have a fairly large nonnumeric vocabulary (see Mix et al., 2002b). Given that we as yet have no evidence that Alex understands ordinality but that he does have some level of symbolic use and understanding of number labels, Wiese's (2003) system is difficult to apply to his results.

In contrast to these views, some researchers have suggested that visuospatial, not linguistic, knowledge and memory are more important for development of cardinality (Ansari et al., 2003; McLean \& Hitch, 1999; Semrud-Clikeman \& Hynd, 1990), possibly because early number competence may involve magnitude representation-number lines, proportion of area, or similar mental constructs (Mix et al., 2002b). Given that most animals tested on number competence, including parrots, have evolutionarily selected visuospatial reasoning abilities related to foraging, this possibility is worth considering. However, Alex's competence with intermixed objects of various shapes and sizes and trials in which smaller quantities had larger areas suggests he was not responding on the basis of visuospatial capacities.

Another issue that cannot at present be resolved involves what Carey (2004) called the successor relation. Children, once they begin to grasp counting (i.e., truly understand the meaning of five), immediately recognize that a new number label is connected to a new quantity and that each new label in a series is exactly one more than the one before. Chimpanzees (e.g., Kawai \& Matsuzawa, 2000) do not seem to understand this concept; each larger number label required the same amount of training as the previous one. For Alex, because labels that have novel phonemes require him to learn new vocal tract control patterns (e.g., Warren, Patterson, \& Pepperberg, 1996), acquisition of new number labels is constrained by more than quantity recognition. Of relevance are experiments to determine whether Alex has developed a sense of ordinality of his number labels without having had formal instruction; remember that his number labels were not taught in numerical order (Pepperberg, 1987).

Most probably, Alex's competence (and likely that of various trained apes) presents an intriguing intermediary between the abilities of young children who are first learning both language and number and older children with more sophisticated numerical and linguistic knowledge. Alex may indeed have exceptional perceptual mechanisms (i.e., a capacity to subitize up to 6); such an explanation of his data is possible, even given the confounded arrays he was given. If Alex used an iconic representation of number (e.g., Wiese, 2003), then he has an as yet untested understanding of ordinality. We believe instead that Alex has some internal representation of his number labels; how these representations correspond to those of humans is, however, unclear. 


\section{Future Directions}

We still do not know if Alex counts in the accepted, human sense (Fuson, 1988). We have not shown that he understands that number labels represent an ordered set of tags that can be paired with each object or in which each tag constitutes one more individual item than the previous tag. Studies to demonstrate explicitly Alex's sense of ordinality are underway (Pepperberg, 2005) because simple ordered vocal production (i.e., "one, two, three, . ...") may indicate only rote memorization (e.g., Dehaene, 1992). And demonstrating one-to-one pairing is complicated: Parrot claws and beaks are less suitable than primate digits for pointing (Pepperberg, 1988b), and training Alex to produce specific actions, such as small head movements in the direction of the targeted objects, would increase the likely use of rhythmic patterns or sequential subitizing (Davis \& Pérusse, 1988). We are also beginning to examine Alex's abilities to add small quantities and plan to test his understanding of the subtraction of small amounts.

\section{Conclusion}

We note that although Alex is unique in that he has over two decades of training on human vocal communication, he is not unlike chimpanzees similarly trained nonvocally: for example, Ai (Biro \& Matsuzawa, 2001), Sheba (Boysen \& Bernsten, 1989, 1990), and Sarah (Boysen \& Bernsten, 1989, 1990; Premack, 1983). All such animals are special in that they have been extensively enculturated to human cognitive tasks. Nevertheless, these animals' achievements suggest that numerical concepts beyond those involving small quantities (i.e., up to 4) are within the basic toolbox of at least some nonhumans; it is unlikely that Alex or any nonhuman can be trained in such concepts de novo (Pepperberg, 1999; Rice, 1980). These animals' ability to learn in the laboratory must be based on an existent cognitive architecture; their training merely provides a way of examining the extent to which this architecture matches that of humans. As argued previously (Pepperberg, 1994a), the value of research about number lies mainly in its use as a step toward determining the extent of animal cognitive competence: in determining whether the observed abilities can be developed into more complex capacities. We again claim that in such a manner, numerical competence may indeed become a comparative indicator of general intelligence.

\section{Notes}

${ }^{1}$ Irene M. Pepperberg was out of town in October 2003, and given the need to ensure that all appropriate controls were in place during testing, no testing occurred in her absence.

${ }^{2}$ This percentage represented 106 matches of 108 vocalizations. As an additional control, Irene M. Pepperberg made two transcriptions of a student, new to the lab, as he responded to the same type of questions as Alex. The first transcription was live; the second, made several days later, was of a tape from which all questions had been edited. The two transcriptions of the student's vocalizations matched to within $95.8 \%$ (68 of 71 vocalizations).

${ }^{3}$ If we indeed factored this possibility of error into our calculations, we would have to use a chance value of 1/10, rather than 1/2, for Experiment 1 and a chance value of 1/15, rather than 1/3, for Experiment 2 . As noted, we decided to use the more conservative value of chance.

${ }^{4}$ As noted in the Discussion, noncompliance is most common when familiar objects are repeatedly used as rewards. Here we had to use familiar items for trials in which Alex was asked to identify the object, and in order not to cue him in any way about the type of trial other than by the oral question posed, we also had to use familiar objects for the trials in which he was asked to identify the color. One attempt to break 
this rule, with jelly beans, did not remove the problem fully; our other attempts, in which we used slightly novel and thus commercially dyed paper rings and wooden sticks, seemed to have caused the color confounds.

${ }^{5}$ On one trial during a comprehension study, Alex had been asked "What object purple?" when no purple object was present in an attempt to determine if he would use "none"; he requested a grape (Pepperberg, 1990). Although the likelihood of his requesting that particular item was small (1/11 even if we restrict chance to foods he could label at the time rather than his entire repertoire), the request could simply have been one of his frequent requests for treats during sessions. We did not pursue this line of inquiry further.

${ }^{6}$ Alex's "none" is unlikely to be related to a child's "allgone": He did not use the term after eating all the jelly beans or after tossing all the blocks to the floor, which is the common response of children.

${ }^{7}$ Full understanding of the symbolic label would mean an immediate correlation between hearing "six" and being able to indicate a set of six items. The stage described by Huttenlocher et al. (1994), however, appears to involve a one-to-one correlation of the label 6 with a mental representation of six tokens and then a one-to-one correlation between the group of tokens and the to-be-quantified set.

${ }^{8}$ This numerical randomness is another reason why phonemic or color confounds present more likely explanations of his errors than does a misunderstanding of what number labels represent.

\section{References}

Ansari, D., Donlan, C., Thomas, M. S. C., Ewing, S. A., Pen, T., \& Karmiloff-Smith, A. (2003). What makes counting count? Verbal and visuo-spatial contributions to typical and atypical number development. Journal of Experimental Child Psychology, 85, 50-62.

Beran, M. J. (2001). Summation and numerousness judgments of sequentially presented sets of items by chimpanzees (Pan troglodytes). Journal of Comparative Psychology, 115, 181-191.

Beran, M. J. (2004). Chimpanzees (Pan troglodytes) respond to nonvisible sets after one-by-one addition and removal of items. Journal of Comparative Psychology, 118, 25-36.

Beran, M. J., \& Rumbaugh, D. M. (2001). "Constructive" enumeration by chimpanzees (Pan troglodytes) on a computerized task. Animal Cognition,4, 81-89.

Bialystok, E., \& Codd, J. (2000). Representing quantity beyond whole numbers: Some, none and part. Canadian Journal of Experimental Psychology, 54, 117-128.

Biro, D., \& Matsuzawa, T. (2001). Use of numerical symbols by the chimpanzee (Pan troglodytes): Cardinals, ordinals, and the introduction of zero. Animal Cognition, 4, 193-199.

Bowmaker, J. K., Heath, L. A., Das, D., \& Hunt, D. M. (1994). Spectral sensitivity and opsin structure of avian rod and cone visual pigments. Investigative Ophthalmology and Visual Science, 35, 1708.

Bowmaker, J. K., Heath, L. A., Wilkie, S. E., Das, D., \& Hunt, D. M. (1996). Middle-wave cone and rod visual pigments in birds: Spectral sensitivity and opsin structure. Investigative Ophthalmology \& Visual Science, 37, S804.

Boysen, S. T., \& Berntson, G. G. (1989). Numerical competence in a chimpanzee. Journal of Comparative Psychology, 103, 23-31.

Boysen, S. T., \& Berntson, G. G. (1990). The development of numerical skills in the chimpanzee. In S. T. Parker \& K. R. Gibson (Eds.), "Language" and intelligence in monkeys and apes: Comparative developmental perspectives (pp. 435-450). Cambridge, England: Cambridge University Press.

Brannon, E. M., \& Terrace, H. S. (1998, October 23). Ordering of the numerosities 1-9 by monkeys. Science, 282, 746-749. 
Brannon, E. M., \& Terrace, H. S. (2000). Representation of the numerosities 1-9 by rhesus macaques. Journal of Experimental Psychology: Animal Behavior Processes, 26, 31-49.

Brannon, E. M., Wusthoff, C. J., Gallistel, C. R., \& Gibbon, J. (2001). Numerical subtraction in the pigeon: Evidence for a linear subjective number scale. Psychological Science, 12, 238-243.

Burns, R. A. (1988). Subitizing and rhythm in serial numerical investigations with animals. Behavioral and Brain Sciences, 11, 581-582.

Call, J. (2000). Estimating and operating on discrete quantities in orangutans (Pongo pygmaeus). Journal of Comparative Psychology, 114, 136-147.

Carey, S. (2004, Winter). Bootstrapping \& the origin of concepts. Dædalus, 133, 59-68.

Carey, S., \& Spelke, E. (1994). Domain specific knowledge and conceptual change. In L. Hirshfield \& S. Gelman (Eds.), Mapping the mind: Domain specificity in cognition and culture (pp. 169-200). Cambridge, England: Cambridge University Press.

Davis, H., \& Pérusse, R. (1988). Numerical competence in animals: Definitional issues, current evidence, and a new research agenda. Behavioral and Brain Sciences, 11, 561-615.

Dehaene, S. (1992). Varieties of numerical abilities. Cognition, 44, 1-42.

Dehaene, S. (1997). The number sense. Oxford, England: Oxford University Press.

Dehaene, S. (2001). Subtracting pigeons: Logarithmic or linear? Psychological Science, 12, 244-246.

Dehaene, S., \& Changeux, J. (1993). Development of elementary numerical abilities: A neuronal model. Journal of Cognitive Neuroscience, 5, 390-407.

Dehaene, S., Piazza, M., Pinel, P., \& Cohen, L. (2003). Three parietal circuits for number processing. Cognitive Neuropsychology, 20, 487-506.

Dehaene, S., Spelke, E., Pinel, P., Stanescu, R., \& Tsivkin, S. (1999, May 7). Sources of mathematical thinking: Behavioral and brain imaging evidence. Science, 284, 970-974.

Emmerton, J., Lohmann, A., \& Niemann, J. (1997). Pigeons' serial ordering of numerosity with visual arrays. Animal Learning \& Behavior, 25, 234-244.

Feigenson, L., Carey, S., \& Spelke, E. (2002). Infants' discrimination of number vs. continuous extent. Cognitive Psychology, 44, 33-66.

Fuson, K. C. (1988). Children's counting and concepts of number. New York: Springer-Verlag.

Gallistel, C. R., \& Gelman, R. (1991). Subitizing: The pre-verbal counting process. In W. E. Kessen, A. Ortony, \& F. I. M. Craik (Eds.), Thoughts, memories, and emotions: Essays in honor of George Mandler (pp. 65-81). Hillsdale, NJ: Erlbaum.

Gallistel, C. R., \& Gelman, R. (1992). Preverbal and verbal counting and computation. Cognition, 44, 4374.

Geary, D. C., Hamson, C. O., \& Hoard, M. K. (2000). Numerical and arithmetical cognition: A longitudinal study of process and concept deficits in children with learning disability. Journal of Experimental Child Psychology, 77, 236-263.

Gelman, R., \& Gallistel, C. R. (1978). The child's understanding of number. Cambridge, MA: Harvard University Press.

Hauser, M. D., \& Spelke, E. (2004). Evolutionary and developmental foundations of human knowledge. In M. Gazzaniga (Ed.), The cognitive neurosciences (pp. 853-864). Cambridge, MA: MIT Press.

Hermer-Vazquez, L. (1997). Cognitive flexibility as it emerges over evolution and development: The case of human spatial reorientation. Unpublished doctoral dissertation, Cornell University, Ithaca, NY.

Hurford, J. R. (1987). Language and number. Oxford, England: Basil Blackwell.

Huttenlocher, J., Jordan, N., \& Levine, S. C. (1994). A mental model for early arithmetic. Journal of Experimental Psychology: General, 123, 284-296.

Kahneman, D., Treisman, A., \& Gibbs, B. J. (1992). The reviewing of object files: Object specific integration of information. Cognitive Psychology, 24, 175-219.

Kawai, N., \& Matsuzawa, T. (2000, January 6). Numerical memory span in a chimpanzee. Nature, 403, $39-40$. 
Kilian, A., Yaman, S., von Fersen, L., \& Güntürkün, O. (2003). A bottlenosed dolphin discriminates visual stimuli differing in numerosity. Learning \& Behavior, 31, 133-142.

Lavie, N., \& de Fockert, J. W. (2003). Contrasting effects of sensory limits and capacity limits in visual selective attention. Perception \& Psychophysics, 65, 202-212.

Lenneberg, E. H. (1971). Of language, knowledge, apes, and brains. Journal of Psycholinguistic Research, 1, 1-29.

Lyon, B. E. (2003, April 3). Egg recognition and counting reduce costs of avian conspecific brood parasitism. Nature, 422, 495-499.

Mandler, G., \& Shebo, B. J. (1982). Subitizing: An analysis of its component processes. Journal of Experimental Psychology, General, 111, 1-22.

May, D. L. (1995). Numerical competence in Grey parrots. Unpublished master's thesis, University of Arizona, Tucson.

McComb, K., Packer, C., \& Pusey, A. (1994). Roaring and numerical assessment in contests between groups of female lions, Pantera leo. Animal Behaviour, 47, 379-387.

McLean, J. F., \& Hitch, G. J. (1999). Working memory impairments in children with specific arithmetic learning difficulties. Journal of Experimental Child Psychology, 74, 240-260.

Meck, W., \& Church, R. (1983). A mode control model of counting and timing processes. Journal of Experimental Psychology: Animal Behavior Processes, 9, 320-334.

Mitchell, R. W., Yao, P., Sherman, P. T., \& O'Regan, M. (1985). Discriminative responding of a dolphin (Tursiops truncatus) to differentially rewarded stimuli. Journal of Comparative Psychology, 99, 218-225.

Mix, K. (1999). Preschoolers' recognition of numerical equivalence: Sequential sets. Journal of Experimental Child Psychology, 74, 309-332.

Mix, K., Huttenlocher, J., \& Levine, S. C. (2002a). Multiple cues for quantification in infancy: Is number one of them? Psychological Bulletin, 128, 278-294.

Mix, K., Huttenlocher, J., \& Levine, S. C. (2002b). Quantitative development in infancy and early childhood. New York: Oxford University Press.

Murofushi, K. (1997). Numerical matching behavior by a chimpanzee (Pan troglodytes): Subitizing and analogue magnitude estimation. Japanese Psychological Research, 39, 140-153.

Nieder, A., Freedman, D. J., \& Miller, E. K. (2002, September 6). Representation of the quantity of visual items in the primate prefrontal cortex. Science, 297, 1708-1711.

Olthof, A., Iden, C. M., \& Roberts, W. A. (1997). Judgments of ordinality and summation of number symbols by squirrel monkeys (Saimiri sciureus). Journal of Experimental Psychology: Animal Behavior Processes, 23, 325-333.

Orlov, T., Yakovlev, V., Amit, D., Hochstein, S., \& Zohary, E. (2002). Serial memory strategies in macaque monkeys: Behavioral and theoretical aspects. Cerebral Cortex, 12, 306-317.

Peignot, P., \& Anderson, J. R. (1999). Use of experimenter-given manual and facial cues by gorillas (Gorilla gorilla) in an object-choice task. Journal of Comparative Psychology, 113, 253-260.

Pepperberg, I. M. (1981). Functional vocalizations by an African Grey parrot. Zeitschrift für Tierpsychologie, 55, 139-160.

Pepperberg, I. M. (1987). Evidence for conceptual quantitative abilities in the African Grey parrot: Labeling of cardinal sets. Ethology, 75, 37-61.

Pepperberg, I. M. (1988a). Comprehension of "absence" by an African Grey parrot: Learning with respect to questions of same/different. Journal of the Experimental Analysis of Behavior, 50, 553-564.

Pepperberg, I. M. (1988b). An interactive modeling technique for acquisition of communication skills: Separation of "labeling"' and "requesting" in a psittacine subject. Applied Psycholinguistics, 9, 5976.

Pepperberg, I. M. (1990). Cognition in an African Gray parrot (Psittacus erithacus): Further evidence for comprehension of categories and labels. Journal of Comparative Psychology, 104, 41-52. 
Pepperberg, I. M. (1992). Proficient performance of a conjunctive, recursive task by an African gray parrot (Psittacus erithacus). Journal of Comparative Psychology, 106, 295-305.

Pepperberg, I. M. (1994a). Evidence for numerical competence in an African gray parrot (Psittacus erithacus). Journal of Comparative Psychology, 108, 36-44.

Pepperberg, I. M. (1994b). Vocal learning in Grey Parrots (Psittacus erithacus): Effects of social interaction, reference, and context. Auk, 111, 300-313.

Pepperberg, I. M. (1999). The Alex studies: Cognitive and communicative abilities of Grey parrots. Cambridge, MA: Harvard University Press.

Pepperberg, I. M. (2005). Ordinal number comprehension by a Grey Parrot (Psittacus erithacus) via a stimulus equivalence task. Manuscript in preparation.

Pepperberg, I. M., \& Brezinsky, M. V. (1991). Acquisition of a relative class concept by an African gray parrot (Psittacus erithacus): Discriminations based on relative size. Journal of Comparative Psychology, 105, 286-294.

Pepperberg, I. M., \& Kozak, F. A. (1986). Object permanence in the African Grey parrot (Psittacus erithacus). Animal Learning \& Behavior, 14, 322-330.

Pepperberg, I. M., \& Lynn, S. K. (2000). Perceptual consciousness in Grey parrots. American Zoologist, 40, 393-401.

Pepperberg, I. M., Naughton, J. R., \& Banta, P. A. (1998). Allospecific vocal learning by Grey parrots (Psittacus erithacus): A failure of videotaped instruction under certain conditions. Behavioural Processes, 42, 139-158.

Pepperberg, I. M., \& Sherman, D. (2000). Proposed use of two-part modeling as a means to increase functional skills in children with a variety of disabilities. Teaching and Learning in Medicine, 12, 213-220.

Pepperberg, I. M., \& Wilkes, S. R. (2004). Lack of referential vocal learning from LCD video by Grey Parrots (Psittacus erithacus). Interaction Studies, 5, 75-97.

Premack, D. (1976). Intelligence in ape and man. Hillsdale, NJ: Erlbaum.

Premack, D. (1983). The codes of man and beast. Behavioral and Brain Sciences, 6, 125-176.

Reiner, A., Perkel, D. J., Bruce, L. L., Butler, A. B., Csillag, A. S., Kuenzel, W., et al. (2004). Revised nomenclature for avian telencephalon and some related brainstem nuclei. Journal of Comparative Neurology, 473, 377-414.

Rice, M. (1980). Cognition to language: Categories, word meanings, and training. Baltimore: University Park Press.

Rumbaugh, D. M., Savage-Rumbaugh, E. S., \& Hegel, M. (1987). Summation in a chimpanzee (Pan troglodytes). Journal of Experimental Psychology: Animal Behavior Processes, 13, 107-115.

Savage-Rumbaugh, E. S., Murphy, J., Sevcik, R. A., Brakke, K. E., Williams, S. L., \& Rumbaugh, D. M. (1993). Language comprehension in ape and child. Monographs of the Society for Research in Child Development, 233, 1-258.

Savage-Rumbaugh, E. S., Rumbaugh, D. M., \& Boysen, S. (1980). Do apes use language? American Scientist, 68, 49-61.

Seibt, U. (1982). Zahlbegriff und Zahlverhalten bei Tieren. Neue Versuche und Deutungen [Number concepts and number behavior by animals: New experiments and interpretations]. Zeitschrift für Tierpsychologie, 60, 325-341.

Semrud-Clikeman, M., \& Hynd, G. W. (1990). Right hemisphere dysfunction in nonverbal learning disabilities: Social, academic, and adaptive functioning in adults and children. Psychological Bulletin, 107, 196-209.

Shumaker, R. W., Palkovich, A. M., Beck, B. B., Guagnano, G. A., \& Morowitz, H. (2001). Spontaneous use of magnitude discrimination and ordination by the orangutan (Pongo pygmaeus). Journal of Comparative Psychology, 115, 385-391. 
Simon, T. J. (1997). Reconceptualizing the origins of number knowledge: A "non-numerical" account. Cognitive Development, 12, 349-372.

Smirnova, A. A., Lazareva, O. F., \& Zorina, Z. A. (2000). Use of number by crows: Investigation by matching and oddity learning. Journal of the Experimental Analysis of Behavior, 73, 163-176.

Smith, B. R., Piel, A. K., \& Candland, D. K. (2003). Numerity of a socially housed hamadryas baboon (Papio hamadryas) and a socially housed squirrel monkey (Saimiri sciureus). Journal of Comparative Psychology, 117, 217-225.

Spelke, E. S., \& Tsivkin, S. (2001). Language and number: A bilingual training study. Cognition, 78, 4588.

Sulkowski, G. M., \& Hauser, M. D. (2001). Can rhesus monkeys spontaneously subtract? Cognition, 79, 239-262.

Thomas, R. K. (1992). Primates' conceptual use of number: Ecological perspectives and psychological processes. In T. Nishida, W. C. McGrew, P. Marler, M. Pickford, \& F. B. M. de Waal (Eds.), Topics in primatology: Vol. I. Human origins (pp. 305-314). Tokyo: University of Tokyo Press.

Thompson, N. S. (1968). Counting and communication in crows. Communications in Behavioral Biology, 2, 223-225.

Thompson, N. S. (1969). Individual identification and temporal patterning in the cawing of common crows. Communications in Behavioral Biology, 4, 29-33.

Treisman, A., \& Gelade, G. (1980). A feature integration theory of attention. Cognitive Psychology, 12, 97-136.

Treisman, A., \& Souther, J. (1985). Search asymmetry: A diagnostic for preattentive processing of separable features. Journal of Experimental Psychology: General, 114, 285-310.

Trick, L., \& Pylyshyn, Z. (1989). Subitizing and the FNST spatial index model (COGMEM \#44). University of Western Ontario, London, Ontario, Canada.

Trick, L., \& Pylyshyn, Z. (1994). Why are small and large numbers enumerated differently? A limitedcapacity preattentive stage in vision. Psychological Review, 101, 80-102.

Vick, S.-J., \& Anderson, J. R. (2003). Use of human visual attention cues by olive baboons (Papio anubis) in a competitive task. Journal of Comparative Psychology, 117, 209-216.

von Glasersfeld, E. (1981). An attention model for the conceptual construction of units and number. Journal of Research in Mathematical Education, 12, 83-94.

von Glasersfeld, E. (1982). Subitizing: The role of figural patterns in the development of numerical concepts. Archives de Psychologie, 50, 191-218.

Wakely, A., Rivera, S., \& Langer, J. (2000). Can young infants add and subtract? Child Development, 71, 1525-1534.

Warren, D. K., Patterson, D. K., \& Pepperberg, I. M. (1996). Mechanisms of American English vowel production in a Grey parrot (Psittacus erithacus). Auk, 113, 41-58.

Waxman, S. R., \& Markow, D. B. (1995). Words as invitations to form categories: Evidence from 12- to 13-month-old infants. Cognitive Psychology, 29, 257-302.

Wellman, H. M., \& Miller, K. F. (1986). Thinking about nothing: Development of concepts of zero. British Journal of Developmental Psychology, 4, 31-42.

West, R. E., \& Young, R. J. (2002). Do domestic dogs show any evidence of being able to count? Animal Cognition, 5, 183-186.

Wiese, H. (2003). Iconic and non-iconic stages in number development: The role of language. Trends in Cognitive Sciences, 7, 385-390.

Wolfgramm, J., \& Todt, D. (1982). Pattern and time specificity in vocal responses of blackbirds Turdus merula L. Behavior, 81, 264-286.

Wynn, K. (1990). Children's understanding of counting. Cognition, 36, 155-193.

Xia, L., Emmerton, J., Siemann, M., \& Delius, J. D. (2001). Pigeons (Columba livia) learn to link numerosities with symbols. Journal of Comparative Psychology, 115, 83-91. 
Xia, L., Siemann, M., \& Delius, J. D. (2000). Matching of numerical symbols with number of responses by pigeons. Animal Cognition, 3, 35-43.

\section{Appendix}

All Trials Presented to Alex in Experiment 1

\begin{tabular}{|c|c|c|c|}
\hline Trial no. & Objects & Question & Response \\
\hline 1 & 2 yellow plastic cups, 1 blue plastic cup & What color 2? & Yellow \\
\hline 2 & 5 gray $^{\mathrm{a}}$ wood blocks, 3 orange wood blocks & What color $5 ?$ & Gray \\
\hline 3 & 4 green plastic cups, 3 rose $^{\mathrm{b}}$ plastic cups & What color $4 ?$ & Green \\
\hline 4 & 6 orange wood blocks, 3 gray wood blocks & What color $6 ?$ & Orange \\
\hline 5 & 2 rose metal keys, 3 purple metal keys & What color $2 ?$ & Rose \\
\hline 6 & 3 blue wood blocks, 2 yellow wood blocks & What color $3 ?$ & Yellow, blue \\
\hline 7 & 6 green pasta spirals, 2 orange pasta spirals & What color $6 ?$ & Green \\
\hline 8 & 4 purple plastic cups, 2 blue plastic cups & What color $4 ?$ & Purple \\
\hline 9 & 5 rose wool pompons, 4 green wool pompons ${ }^{c}$ & What color $5 ?$ & Rose \\
\hline 10 & 2 orange wood rods, 1 purple wood rod & What color 2? & Orange \\
\hline 11 & 4 blue wool pompons, 6 green wool pompons & What color $4 ?$ & Green, blue \\
\hline 12 & 3 blue wood sticks, 5 yellow wood sticks & What color $3 ?$ & Blue \\
\hline 13 & 2 gray metal keys, 4 orange metal keys & What color 2? & Gray \\
\hline 14 & 4 orange wood rods, 5 blue wood rods & What color $4 ?$ & Orange \\
\hline 15 & 6 purple wood blocks, 4 orange wood blocks & What color $6 ?$ & Purple \\
\hline 16 & 5 green wood sticks, 2 purple wood sticks & What color $5 ?$ & Green \\
\hline 17 & 3 gray wool pompons, 1 yellow wool pompon ${ }^{c}$ & What color $3 ?$ & Gray \\
\hline 18 & 4 rose wood blocks, 1 gray wood block & What color $4 ?$ & Rose \\
\hline 19 & 3 yellow wood sticks, 4 blue wood sticks & What color $3 ?$ & Yellow \\
\hline 20 & 5 orange plastic cups, 1 purple plastic cup ${ }^{d}$ & What color 5 ? & Orange \\
\hline 21 & 1 purple plastic key, 2 rose plastic keys & What color $1 ?$ & Purple \\
\hline 22 & 2 blue wood blocks, 6 green wood blocks & What color 2? & Blue \\
\hline 23 & 1 gray wood stick, 2 rose wood sticks & What color $1 ?$ & Gray \\
\hline 24 & 5 yellow paper strips, 6 blue paper strips & What color $5 ?$ & Green, yellow \\
\hline 25 & 1 orange plastic spool, 4 green plastic spools & What color $1 ?$ & Orange \\
\hline 26 & 6 purple wood sticks, 5 yellow wood sticks & What color $6 ?$ & Purple \\
\hline 27 & 3 rose wood rods, 6 gray wood rods ${ }^{c}$ & What color $3 ?$ & Rose \\
\hline 28 & 2 yellow wool pompons, 5 orange wool pompons & What color $2 ?$ & Yellow \\
\hline 29 & 1 gray wood block, 6 blue wood blocks & What color $1 ?$ & Gray \\
\hline 30 & 6 blue wood sticks, 1 green wood stick & What color $6 ?$ & Blue \\
\hline 31 & 1 green plastic cup, 5 purple plastic cups & What color $1 ?$ & Green \\
\hline 32 & 5 rose wool pompons, 6 orange wool pompons & What color 5 ? & Rose \\
\hline
\end{tabular}

a "Gray" is a range of colors from silver to black (on the basis of the fact that the parrot's feathers comprise such a range).

b "Rose" is Alex's label for red; see Pepperberg (1981).

${ }^{c}$ The smaller quantity was represented by objects that were individually bigger than those in the larger quantity (e.g., the smaller number of woollen pompons were made up of pompons of larger radii than the pompons comprising the larger number).

${ }^{d}$ The size of cups in this trial were about 30\% smaller than those in Trial 31. 